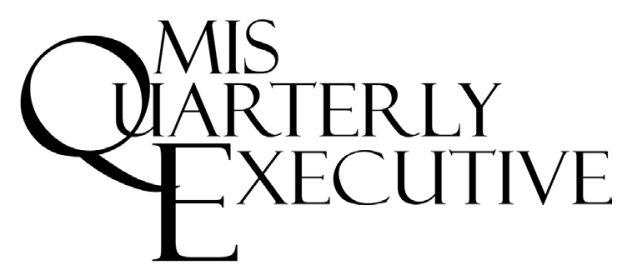

\title{
Three Differentiation Strategies for Competing in the Sharing Economy
}

Executives of organizations entering the sharing economy face the challenge of selecting the right differentiation strategy. This article describes three sharing economy differentiation strategies - technology, partnership, and user experience. We provide nine questions to guide the selection of a differentiation strategy when entering the sharing economy, and recommend three actions for implementing the strategy. ${ }^{2,3}$

\author{
Alexander Frey \\ University of Augsburg \\ (Germany)
}

\author{
Manuel Trenz \\ University of Augsburg \\ (Germany)
}

\author{
Daniel Veit \\ University of Augsburg \\ (Germany)
}

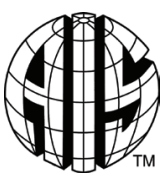

$\Psi$

KELLEY SCHOOL OF BUSINESS

\section{The Dynamics of the Sharing Economy}

In 2015, Business Insider published an article about the world's five most valuable startups. ${ }^{3}$ Two of these were sharing economy firms-Uber, the peer-to-peer ridesharing service, with a valuation of $\$ 69$ billion and Airbnb, the online accommodation marketplace, with a valuation of $\$ 30$ billion. The sharing economy emphasizes access over ownership and is growing rapidly. Some argue that the sharing economy has the potential to become as important as the industrial revolution in terms of the way we think about ownership and that it is shaping the next stage in the evolution of economies. ${ }^{4}$

The main facilitators of novel sharing-oriented business models are technologies such as Web 2.0, social media, and smartphones with mobile Internet. ${ }^{5}$ In contrast to pure digital platforms, the sharing economy blurs the boundaries between the physical and virtual worlds by facilitating the sharing of physical products (for example, power drills) or the provision of non virtual services (for example, ridesharing). Thus, organizations participating in the sharing economy face both digital challenges (e.g., network effects of a two-sided digital market) and physical challenges (e.g., the handover of shared resources).

Including physical components in the digital world enables new ways of creating value that go beyond utility-for instance, through social value gained from the participants meeting each other (e.g., by having a nice conversation), or through a sensory experience while using a

\footnotetext{
1 Hope Koch is the accepting senior editor for this article.

2 This study is part of a larger project on the impact of the sharing economy in Germany. The project is funded by the German Federal Ministry of Education and Research. For further information see: www.i-share-economy.org.

3 Kosoff, M. “The \$20 Billion Club: Meet the 5 Most Valuable Startups in the World,” Business Insider, June 26, 2015, available online at http://www.businessinsider.com/the-20-billion-club-meet-the-5-most-valuable-startups-in-the-world-2015-6.

4 Botsman, R. and Rogers, R. "What's Mine Is Yours: The Rise of Collaborative Consumption (1st edition)", Harper Business, 2010 .

5 Trenz, M., Frey, A. and Veit, D. "Disentangling the Facets of Sharing: A Categorization of What We Know and Don't Know About the Sharing Economy," Internet Research (28:4), 2018.
} 
certain resource (e.g., excitement when driving a sports car that otherwise wouldn't be affordable).

There are a growing number of examples of sharing economy businesses disrupting traditional industries (e.g., hotels and taxis), and these examples highlight the significant potential impact of the sharing economy on both society and established industries. This impact has caused more firms to engage in the sharing economy. However, there are also many examples of sharing economy businesses that have failed (e.g., Sidecar and carpooling.com). ${ }^{6}$ Increased interest and prominent failure cases highlight the need to identify suitable strategies for competing in the sharing economy.

Many traditional businesses see cost leadership as the way to gain a competitive advantage. In contrast, sharing economy organizations often rely on people (e.g., drivers) providing their own resources, and a strategy of offering the lowest prices for the shared resources may discourage resource owners who are seeking to generate an income from their products or services from signing up with the sharing platform. As shown by the ongoing price competition between ride-for-hire services Uber and Lyft, a cost leadership approach results in a price race to the bottom. While revenue shortfalls could be offset in the short term by supply-side subsidies, an enduring price-leadership approach is very risky. Sharing economy firms must therefore identify other differentiation strategies if they are to compete successfully in the long run.

Given that the sharing economy is based on digital platforms that enable new ways of creating value, technology can be an important means for sharing economy firms to differentiate their offerings. Uber, for example, has developed technology that allows very efficient and fast mediation between drivers and potential passengers. However, platforms such as BlaBlaCar (an online marketplace for carpooling) and Airbnb focus on the experiences customers can have by using the platform and don't exploit technology as a competitive feature. Other companies like SWA Carsharing (a German regional car sharing provider) use standard technology for providing their services. This

6 Täuscher, K. and Kietzmann, J. "Learning from Failures in the Sharing Economy," MIS Quarterly Executive (16:4), December 2017, pp. 253-264. indicates that, in addition to technology, there are several other differentiation strategies that firms entering the sharing economy can adopt. However, determining which strategy would be best in which situation remains a major challenge.

The purpose of this article is to provide advice for executives of firms entering the sharing economy on how to select an appropriate differentiation strategy. Our insights were derived from interviews with managers of sharing economy organizations in a range of sectors. (Our research method is described in Appendix A.) From our research, we have identified three differentiation strategies-technology, partnership and user experience-and illustrate them using three case examples. We explain and discuss the applicability of each strategy and translate our insights into nine questions that managers should ask when selecting their sharing economy differentiation strategy.

\section{Cases Illustrating the Three Sharing Economy Differentiation Strategies}

Even though technology is a main driver for the sharing economy and plays an important role in the value creation process, and even though the services are heavily based on technology, many of the organizations we investigated do not exploit technology as a resource to gain competitive advantage. Instead, they differentiate themselves by following a partnership or userexperience strategy. From our large database of sharing economy organizations, we have selected three-Uber, SWA Carsharing, and BlaBlaCarto illustrate the three differentiation strategies. These three case organizations were selected because they exemplify each of the strategies. Table 1 provides an overview of the three cases.

\section{Uber: An Example of the Technology Differentiation Strategy}

Companies following this strategy use technology to differentiate their business from competitors. They leverage technology to discover novel opportunities for service provision or use it to create a unique service. Uber is as a prime example of the technology differentiation strategy. 
Table 1: Case Descriptions

\begin{tabular}{|l|l|l|l|}
\hline Organization & Description & $\begin{array}{c}\text { Owns } \\
\text { Resource? }\end{array}$ & Scope \\
\hline Founded
\end{tabular}

On the one hand, Uber leverages technology to discover potentially new ways of providing services. To achieve this, it collects large amounts of data on the users and the shared resources and uses data mining techniques on the collected data. Data mining enables Uber to uncover unused capacity and to expand its business by, for example, adding delivery services for food and parcels:

"Once the systems are running in the cities, you can strap on ... food delivery or ... parcel delivery." General Manager, Uber

On the other hand, Uber's focus on technology enables it to be more efficient than competitors. For instance, Uber uses unique algorithms that increase the efficiency of the platform by pooling formerly unrelated transactions:

"The system recognizes, when you are arriving ... and takes this calculation into account in advance ... to patch that with the next ride [of that driver]. ... Through this technology you will get a car which is closer to you. ... [But] implementing [that] technology is hard to achieve." General Manager, Uber
The efficiency enabled by its unique technology also helps Uber survive in a mature market with competing services like Lyft:

"Technology is a principal point to compete in mature markets. ... If you want to decrease the waiting time ... a huge amount of engineering work is necessary to reduce it [by just] 15 seconds. At some point the system is so efficient, that you have to invest a lot of effort [to improve it further]." General Manager, Uber

This quote also highlights that, if two competing companies follow the same differentiation strategy, marginal differences can play a role in users' decision-making, and that a lot of effort is required to achieve those marginal differences.

In summary, Uber has used advanced technology to create an expandable service and a highly efficient platform. As highlighted by the following quote, both of these are central to Uber's success:

"At the end of the day, the robustness and deep intelligence of the platform are our unique selling point." Head of Public Affairs, Uber

Other sharing economy companies have leveraged self-developed technology as a resource 
to gain a competitive advantage. Some car sharing providers, for instance, have created new options for connecting the physical and digital worlds by developing unique hardware for the keyless opening and starting of vehicles.

\section{SWA Carsharing: An Example of the Partnership Differentiation Strategy}

The partnership strategy is another approach for differentiating sharing economy firms. Organizations following this strategy use partnerships to position themselves against competitors by signing contracts to obtain (exclusive) access to resources and infrastructure, or to offer value-adding services for their users. SWA Carsharing provides an example of the partnership differentiation strategy.

SWA Carsharing signs exclusive contracts with owners of the resources and infrastructure needed to provide services that potential competitors could not offer, or to mediate resources that competitors do not have access to:

"If you try to find a parking space in the historic [Augsburg] city center, you won't find one. That's the challenge. Therefore, municipalities are an important partner for us." General Manager, SWA Carsharing

SWA Carsharing also uses partnerships to provide complementary services or to scale the business by extending the physical boundaries of the service. Its services are focused on short distances in one city, which means its customers could be at a disadvantage compared to customers of international car sharing providers like car2go or DriveNow. To address this problem, SWA Carsharing uses standard technology and cooperates with other car sharing providers using the same technology to offer customers a nationwide service:

"Our users can book nationwide vehicles [of other car sharing providers]. Vice versa, their users can use our vehicles." Head of Sales, SWA Carsharing

By leveraging the networks of other services, SWA Carsharing is able to add additional value to its services and overcome the potential disadvantages of just being a regional operator.

Other sharing economy organizations typically use partnerships to offer complementary services such as insurance to cover potential damage to the shared resources, or to connect to other ecosystems for marketing and scalability purposes.

\section{BlaBlaCar: An Example of the User- Experience Differentiation Strategy}

The third sharing economy differentiation strategy is to create unique user experiences. Instead of simply offering a product, an experience is sold, with the experience being generated through social interaction or through the resource itself.

As a long-distance ridesharing service, social aspects and interaction are very important for BlaBlaCar. Users of BlaBlaCar's service want to know with whom they will be interacting, and they may even choose a ride that is able to highlight this interaction. The social component is therefore very important for BlaBlaCar:

"We know that for a lot of drivers the social [dimension] is very important. If you drive 600 kilometers every week, people get bored sometime." Head of Marketing, BlaBlaCar

BlaBlaCar leverages the importance of social interaction on its platform by providing online profiles, which include a user's selfdescription, interests or preferences, and provides information on the user's willingness to communicate. BlaBlaCar's marketing activities therefore focus on how much fun it is to share a ride:

"[By using BlaBlaCar] people [get to] meet younger people [whom] they normally wouldn't have met. They have a nice conversation, [and] the time [during the ride seems to go faster]. That's very central [to our offering]. Our marketing is focused on that aspect." Head of Marketing, BlaBlaCar

Experiences with the resource itself can also be used to differentiate a sharing economy business. One way to leverage resource experiences is to offer access to unique and exclusive resources, such as an upmarket penthouse apartment or a historic castle listed on an accommodation-sharing service like Airbnb or Wimdu.

In summary, the user-experience differentiation strategy focuses on enjoyment when using a sharing economy service. With 
this strategy, efficiency and the time required to mediate the service play minor roles.

\section{Questions to Ask When Selecting a Sharing Economy Differentiation Strategy}

Each of the three sharing economy differentiation strategies is suitable for different types of sharing organizations, depending on the characteristics of their competitive environment and their shared resources.

Based on the insights gained from our cases on the applicability of and reasons for selecting a particular differentiation strategy, we have derived nine strategic questions (five relating to competitive characteristics and four to shared resource characteristics). Managers of sharing economy organizations can use these questions to help them select suitable differentiation strategies for their businesses.

\section{Competitive Characteristics}

The competitive characteristics of a sharing economy organization are determined by the value the organization wants to generate for its customers, the competitive environment, the reach of the business, and its capabilities.

Question 1: What Kind of Value Does Your Platform Create? Our research shows that the connection of the digital and physical worlds and the characteristics of resources offered enable sharing economy firms to generate three main types of value: functional (e.g., by increasing the efficiency of a mediation), experiential (e.g., by offering access to a sports car), and social (e.g., by connecting formerly unknown individuals). The type of value created through the sharing platform has direct implications for the firms' differentiation strategies.

Functional value focus: If the platform creates functional value, either a technology or partnership differentiation strategy is suitable. For services where the functional value for users derives from a focus on efficiency, the technology differentiation strategy is appropriate. This strategy should be selected if the perceived quality of the service is mainly defined by the speed of the human-computer interaction. For instance, Uber constantly tries to reduce the waiting time for rides by developing unique algorithms that increase the efficiency of the service.

In contrast, the partnership differentiation strategy is relevant for platforms that create quality-related functional value. SWA Carsharing, for instance, increases the quality of its service by using partnerships to get exclusive access to parking spaces in the center of Augsburg.

Experiential or social value focus: If the platform creates experiential or social value, the user-experience differentiation strategy is appropriate. This strategy is particularly suitable for firms that want to highlight social activities as part of their offerings (e.g., conversations or meeting new people). People will use these firms' platforms because they want to get in contact with others or want to have fun by consuming a particular resource. The time and effort needed to complete a successful transaction and speed of executing the transaction are less important for users. For instance, BlaBlaCar's marketing emphasizes social interaction and the corresponding pleasurable experience of using its service.

Question 2: Do You Compete with Traditional Industries? The business environment in which a sharing economy firm operates must be considered when selecting a differentiation strategy. The sharing economy is often seen as a disruptor for different industries, because many sharing organizations either offer cheaper prices than traditional companies or provide a novel and superior user experience. A prime example is Uber, which, by offering taxi services in a very convenient manner, is often perceived as a disruptor of the taxi industry. Other organizations like SWA Carsharing offer services that formerly did not exist. When answering this question, a sharing economy firm needs to consider whether it operates in an emerging or a mature market.

Emerging market: If a sharing economy firm operates in a new and emerging market without big traditional players, and the firm is in an early stage of development, it should adopt a differentiation strategy that requires low financial investments. This means that the partnership or user-experience differentiation strategy should be selected. A firm that enters a new market early could sign exclusive contracts with future partners to prevent competitors from entering 
the market and adopt a partnership strategy where it and its partners use the same resources and infrastructure. Young companies or startups can also select the user-experience differentiation strategy. BlaBlaCar, for instance, highlights the pleasurable experiences enabled by the platform. Both the partnership and user-experience strategies enable a sharing economy organization to establish itself in the marketplace without having to make the large financial investments that would be necessary to develop unique software or hardware.

Mature market: In more mature markets, sharing economy platforms will need to compete with established traditional firms, making it more challenging to pursue the partnership and user-experience differentiation strategies. Key partners needed to differentiate the business, for instance, may already be signed exclusively to established players. Thus, in a mature market, the technology differentiation strategy may be preferable. Consider, for example, a mature market where two sharing services offer the same service, generate the same kind of value, and each have a 50\% market share. A customer would probably choose the service that offers the best usability and the easiest handling, both of which are enabled by a technology differentiation strategy. A prime example is Uber, which constantly seeks to improve the efficiency of its service to gain a competitive advantage over competitors like Lyft and to position itself as an alternative to the traditional taxi industry.

Question 3: What is Your Firm's Focus? Unlike pure digital services, sharing economy organizations connect the digital and physical worlds and, therefore, face both digital and physical challenges. The geographic reach of a sharing economy platform is an important determinant of the best differentiation strategy to adopt. Some firms restrict their activities to one or more cities and districts (e.g., car sharing providers like SWA Carsharing); extending their services to smaller cities or outlying districts would not be profitable. Other platforms, such as Uber, have no geographic limitations.

Regional scope: If the business is focused on a specific region, cooperation with local partners could provide an advantage over national or international competitors. For instance, SWA Carsharing, which operates solely in one city, has an advantage compared to international providers like DriveNow or car2go because of its local knowledge and contacts that enable it to gain access to needed infrastructure (e.g., parking spaces or charging stations for electric vehicles). Furthermore, SWA Carsharing has partnerships with other national car sharing firms, which it integrates into its platform.

National or international scope: Unlike SWA Carsharing, DriveNow and car2go operate in multiple cities worldwide and follow a technology differentiation strategy. For sharing economy firms like these, rolling out a global business by using local partnerships is virtually impossible, so they should select the technology or user-experience differentiation strategy. For instance, Uber (which operates globally) uses the technology differentiation strategy to achieve greater efficiency than competitors. BlaBlaCar also operates internationally, but follows the user-experience differentiation strategy by highlighting the social value gained by connecting different people with different backgrounds or cultures.

Question 4: What Are Your Firm's Technical Capabilities? The effort and financial resources needed for a sharing economy firm to develop more efficient systems than its competitors will differ depending on the maturity of the market. The level of the firm's technical capabilities will determine which differentiation strategy is appropriate.

Low technical capabilities: If the firm's technical capabilities are limited, substantial time and financial resources will be needed to establish the technological know-how for collecting and analyzing big data or developing unique software or hardware. If there is no pressure from competitors to invest in technology, such firms should select either the partnership or user-experience differentiation strategy. For young organizations with limited financial resources, these strategies require less capital expenditure than the technology differentiation strategy. Rather than developing its own software and hardware (which would have stretched its financial resources and technological knowledge), SWA Carsharing uses standard technology in its vehicles. This enables it to cooperate with other local car sharing providers using the same standard technology. 


\section{Table 2: Questions Related to Competitive Characteristics}

\begin{tabular}{|c|c|c|c|c|c|}
\hline Strategic Question & Option & Description & Technology & Partnership & User Experience \\
\hline \multirow{3}{*}{$\begin{array}{l}\text { What kind of value } \\
\text { does your platform } \\
\text { create? }\end{array}$} & Functional & The value for users is functional & $x$ & $x$ & \\
\hline & Experiential & The value for users is experiential & & & $\mathrm{x}$ \\
\hline & Social & The value for users is social & & & $\mathrm{x}$ \\
\hline \multirow{2}{*}{$\begin{array}{l}\text { Do you compete } \\
\text { with traditional } \\
\text { industries? }\end{array}$} & $\begin{array}{l}\text { Emerging } \\
\text { market }\end{array}$ & $\begin{array}{c}\text { The market is new and growing with } \\
\text { only selected competitors }\end{array}$ & & $\mathrm{x}$ & $x$ \\
\hline & $\begin{array}{l}\text { Mature } \\
\text { market }\end{array}$ & $\begin{array}{c}\text { The market is more mature, and } \\
\text { you already have traditional } \\
\text { competitors }\end{array}$ & $x$ & $(X)$ & $(X)$ \\
\hline \multirow{2}{*}{$\begin{array}{l}\text { What is your firm's } \\
\text { focus? }\end{array}$} & Regional & $\begin{array}{l}\text { The business operates regionally } \\
\text { (e.g., in one city or district) }\end{array}$ & & $x$ & \\
\hline & $\begin{array}{c}\text { National/ } \\
\text { International }\end{array}$ & $\begin{array}{l}\text { The business has no regional } \\
\text { limitations }\end{array}$ & $\mathrm{x}$ & & $x$ \\
\hline \multirow{2}{*}{$\begin{array}{l}\text { What are your } \\
\text { firm's technical } \\
\text { capabilities? }\end{array}$} & Low & $\begin{array}{l}\text { The technical capabilities of the firm } \\
\text { are low }\end{array}$ & & $x$ & $x$ \\
\hline & High & $\begin{array}{l}\text { The firm has advanced technical } \\
\text { capabilities }\end{array}$ & $\mathrm{x}$ & $(\mathrm{X})$ & $(X)$ \\
\hline \multirow{2}{*}{$\begin{array}{l}\text { Are external } \\
\text { resources needed? }\end{array}$} & Yes & $\begin{array}{l}\text { External resources (e.g., parking } \\
\text { spaces) are needed for successful } \\
\text { transactions }\end{array}$ & & $x$ & \\
\hline & No & $\begin{array}{l}\text { The firm provides every resource } \\
\text { needed for a successful transaction }\end{array}$ & $x$ & $(X)$ & $x$ \\
\hline
\end{tabular}

High technical capabilities: Sharing economy firms with a high level of technical capabilities should consider adopting the technology differentiation strategy. Uber, for instance, uses data mining to discover novel means of service provision, or develops unique matching and optimization algorithms for reducing the waiting time for rides.

Question 5: Are External Resources Needed? Another factor in determining the best differentiation strategy for a sharing economy firm is whether external resources will be needed to support the business model.

External resources necessary: If external resources or infrastructure are necessary to successfully fulfill a transaction, the sharing economy firm has to ensure that these resources are available to its customers. For instance, competing car sharing providers need parking spaces or charging stations for electric vehicles to successfully run their businesses. The firm that has access to more parking spaces or charging stations has a competitive advantage. Such firms should therefore follow the partnership differentiation strategy. As already mentioned,
SWA Carsharing has contracts with the municipality to get access to parking spaces, particularly in the city center.

No external resources necessary: In theory, sharing economy firms that are not dependent on any external resources could follow any of the three differentiation strategies. In practice, however, such firms should adopt either the technology or user-experience differentiation strategy because the provision of the service does not depend on external resources and, therefore, the business could be scaled without connecting to partners.

Table 2 summarizes the five questions related to competitive characteristics and lists the recommended and applicable differentiation strategies.

\section{Shared Resource Characteristics}

Shared resources are a unique feature of the sharing economy and the nature of the shared resource should be considered when selecting a differentiation strategy.

Question 6: What Are the Characteristics of the Offered Resources? The uniqueness 
and exclusivity of the offered resources should be considered when selecting a differentiation strategy.

Unique, exclusive or expensive offerings: Access to unique, exclusive, or expensive resources (e.g., upmarket apartments or expensive cars) that are not easily accessible for everyone could be a factor for using a particular sharing economy platform. The platform owner can gain a competitive advantage by leveraging those resources and highlighting the experiences of using them. Platforms offering unique, exclusive or expensive resources should therefore adopt the user-experience differentiation strategy.

Commodity offering: If the resources offered on the platform are commodity goods, the experiential advantages are much less evident. Instead, the sharing platform can use the partnership differentiation strategy to get exclusive access to other resources that increase the quality of the service. SWA Carsharing, for example, signs exclusive contracts with the municipality to get access to parking spaces in the city center. By doing this, it enriches its offering of vehicles with resources that competitors cannot offer. Uber has to compete against easily available traditional cab services (a commodity offering), and its challenge is to convince riders to use its services rather than a cab. To achieve this aim, Uber uses technology to make the sharing service more convenient or cheaper than traditional services. In situations like this, the technology differentiation strategy is appropriate.

Question 7: How Standardized Are the Offered Resources? The more diverse the resources offered on the platform are, the more challenging it is to meet the needs of all players involved in a transaction.

Low level of standardization: A wide range of shared rides can be booked through BlaBlaCar, but each ride is provided by a different driver. In other words, there is a large amount of diversity in the resources. Although BlaBlaCar can control which resources are offered on the platform and which passenger is matched to a certain driver, it has no control over the actual execution of the ride (e.g., accuracy of self-provided passenger information or driving style of the driver). Providing mechanisms like ratings, descriptions of the driving style, or the communication level of a particular driver only go so far. In reality, it is virtually impossible to standardize the quality or efficiency of the offered rides, because these are subjective characteristics. Thus, platforms offering resources with a low level of standardization should adopt the partnership or user-experience differentiation strategy.

High level of standardization: If the resources offered have a high level of standardization, the transactions can also be standardized. For car sharing providers like DriveNow or car2go, which own the shared vehicles, every transaction follows the same pattern and can therefore be made as efficient as possible. In this situation, the technology differentiation strategy is the most appropriate.

Question 8: Does Your Firm Own the Shared Resources? The level of diversity of the offered resources and the degree to which transactions can be standardized depends on the ownership of the resources. Sharing economy firms can either provide access to their own resources or facilitate sharing arrangements for resources owned by third parties.

Owned resources: If a shared economy firm owns the resources (e.g., cars) offered for sharing, it has full control over the quality and availability of the shared resource. Car sharing providers, for instance, mostly own the vehicles they grant access to and typically install technology in their cars (e.g., GPS trackers to locate the vehicles). This creates new possibilities on both the user and provider sides of the platform (e.g., booking efficiency gains for the user and better vehicle maintenance for the provider). The most appropriate differentiation strategy is therefore the technology strategy.

External resources: If the platform provider does not own the resources that are offered for sharing, it is difficult to equip the resources with additional hardware. However, the platform provider could offer unique software solutions (e.g., smartphone apps) to increase efficiency and to facilitate a degree of standardization for the transaction-i.e., the provider could follow a technology differentiation strategy. Uber's strategy, for example, is to include unique algorithms and mechanisms in its smartphone app and thereby improve the efficiency of its platform without having to install additional hardware in the cars, which are owned by the drivers, not by Uber. 
The diversity and flexibility of externally owned resources also open the door for following the partnership and user-experience differentiation strategies, which don't require significant technology investments. Offering external resources leads to a variety of supply, which could, in turn, result in a superior user experience. BlaBlaCar leverages this experience and highlights the social value created for users of the platform. With partnerships and exclusive contracts, sharing economy firms not only assure the supply of resources available on the platform but also increase the variety of resources offered. These opportunities and the comparably lower need for financial investment imply that the userexperience or partnership differentiation strategy should be followed.

Question 9: What Is the Fulfillment Time Horizon? When diners order meals in a restaurant, the type of restaurant determines their expectations for how long they should wait for their food. In a fast-food restaurant, people expect to receive their meal within minutes, whereas in a high-class restaurant, the tolerated waiting time is much longer. The same holds true for the sharing economy. For instance, customers booking a ride with Uber want to get from $A$ to
B quickly and spontaneously. They do not want to wait hours to obtain access to the vehicle or a ride. Thus, the preferred differentiation strategy depends on whether the use of the resource is ondemand or scheduled for later.

On-demand: Platforms handling transactions not planned in advance and providing resources that will be used immediately after ordering should focus on efficiency-i.e., they should follow the technology differentiation strategy. In the case of car sharing services, this strategy is appropriate both for short distance rides (e.g., DriveNow and car2go) and on-demand ride-forhire services (e.g., Uber, Lyft, and the Chinese ride-sharing service Didi Chuxing).

Scheduled: Unlike booking a Uber car, reserving an apartment or house on an accommodation-sharing platform is usually scheduled and planned in advance. Long-distance trips booked via ride-sharing services such as BlaBlaCar are also normally planned in advance. Efficiency and transaction speed play minor roles in the mediation of these resources, and the partnership or user-experience differentiation strategies are usually appropriate.

Table 3 summarizes the questions related to the characteristics of the shared resource

\section{Table 3: Questions Related to Shared Resource Characteristics}

\begin{tabular}{|c|c|c|c|c|c|}
\hline Strategic Question & Option & Description & Technology & Partnership & User Experience \\
\hline \multirow{2}{*}{$\begin{array}{l}\text { What are the } \\
\text { characteristics of the } \\
\text { offered resources? }\end{array}$} & $\begin{array}{l}\text { Unique or } \\
\text { expensive }\end{array}$ & $\begin{array}{l}\text { The offered resources are unique } \\
\text { or expensive }\end{array}$ & & & $x$ \\
\hline & Commodity & $\begin{array}{l}\text { The offered resources are } \\
\text { commodity goods }\end{array}$ & $x$ & $x$ & \\
\hline \multirow{2}{*}{$\begin{array}{l}\text { How standardized } \\
\text { are the offered } \\
\text { resources? }\end{array}$} & $\begin{array}{l}\text { Low } \\
\text { standardization }\end{array}$ & $\begin{array}{c}\text { The offered resources are highly } \\
\text { diverse (e.g., different items or } \\
\text { apartments) }\end{array}$ & & $x$ & $x$ \\
\hline & $\begin{array}{c}\text { High } \\
\text { standardization }\end{array}$ & $\begin{array}{c}\text { The offered resources are similar } \\
\text { (e.g., standardized car sharing } \\
\text { vehicles) }\end{array}$ & $x$ & & \\
\hline \multirow{2}{*}{$\begin{array}{l}\text { Does your firm } \\
\text { own the shared } \\
\text { resources? }\end{array}$} & Yes & $\begin{array}{c}\text { The firm owns the resources that } \\
\text { are offered for sharing }\end{array}$ & $x$ & & \\
\hline & No & $\begin{array}{c}\text { The firm doesn't own the } \\
\text { resources that are offered for } \\
\text { sharing }\end{array}$ & $(X)$ & $x$ & $x$ \\
\hline \multirow{2}{*}{$\begin{array}{l}\text { What is the } \\
\text { fulfillment time } \\
\text { horizon? }\end{array}$} & On-demand & $\begin{array}{l}\text { The user expects to consume } \\
\text { the resource immediately after } \\
\text { ordering }\end{array}$ & $x$ & & \\
\hline & Scheduled & $\begin{array}{l}\text { The user orders the resource in } \\
\text { advance and consumes it later }\end{array}$ & & $\mathrm{x}$ & $x$ \\
\hline
\end{tabular}


Table 4: Summary of the Three Sharing Economy Differentiation Strategies

\begin{tabular}{|c|c|c|c|}
\hline Option & Technology & Partnership & User Experience \\
\hline Description & $\begin{array}{c}\text { Discovery of novel } \\
\text { opportunities for service } \\
\text { provision } \\
\text { Creation of unique } \\
\text { services }\end{array}$ & $\begin{array}{l}\text { Access to resources and } \\
\text { infrastructure } \\
\text { Value-adding } \\
\text { partnerships }\end{array}$ & $\begin{array}{c}\text { Social experiences } \\
\text { Resource experiences }\end{array}$ \\
\hline Applicability & $\begin{array}{ll}\text { - } & \text { High standardization } \\
\text { - } & \text { High efficiency } \\
\text { - } & \text { Transactions not } \\
\text { - } & \text { Quanned in advance } \\
\text { comality of human- } \\
\text { defines experience } \\
\text { - } \\
\text { Mature markets }\end{array}$ & $\begin{array}{ll}\text { - } & \text { External resources } \\
& \text { needed } \\
\text { - } & \text { Low budget } \\
\text { - } & \text { Regional focus } \\
\text { - } & \text { Low standardization }\end{array}$ & $\begin{array}{l}\text { - } \quad \text { Low standardization } \\
\text { Services aimed at social } \\
\text { activities } \\
\text { - Sharing of expensive or } \\
\text { exclusive resources }\end{array}$ \\
\hline Case example & Uber & SWA Carsharing & BlaBlaCar \\
\hline
\end{tabular}

and lists the recommended and applicable differentiation strategies.

\section{Comparison of the Three Differentiation Strategies}

The three sharing economy differentiation strategies are not mutually exclusive. Rather, each should be seen as a main strategy that could be complemented by elements of the other two strategies. For instance, Uber follows the technology differentiation strategy to achieve high efficiency and high standardization for the mediated transactions. It can gain a competitive advantage by offering fancy smartphone apps and smart mechanisms to book a ride conveniently and efficiently. However, Uber could also differentiate itself from competitors by facilitating experiences such as offering beverages and other amenities during a ride.

None of the differentiation strategies is intrinsically superior to the others. Because of the variety of services and resources offered in the sharing economy, firms need to analyze the characteristics of their shared resources and their competitive environment to prioritize the three differentiation strategies. In general, strategies should not be easy to copy if technology, unique partnerships, or user experience are at the center of the strategic positioning.

It is worth noting that competing sharing economy firms following the same differentiation strategy have different options for positioning themselves within that strategy. For example, both Uber and Lyft follow the technology differentiation strategy and focus on reducing the waiting time for rides because they realize that marginal differences play a significant role in consumers' decision making when selecting an on-demand ride-for-hire service. In their technological race, Uber was first able to display waiting times and an estimated arrival time even before booking a ride. Lyft, on the other hand, established a colored light on the driver's dashboard that allows passengers to identify their assigned driver more effectively in busy places or at night. Equally, a car sharing service following the partnership differentiation strategy might focus on partnerships to ensure parking spaces for their vehicles, whereas others might leverage partnerships for closely integrating public transport with short-range transit.

Table 4 summarizes the key elements and the applicability of the three sharing economy differentiation strategies.

\section{Recommended Actions for Successfully Implementing a Differentiation Strategy}

Our analysis applies equally to traditional companies and startups that plan to enter the sharing economy. While the same guidelines apply to traditional companies and startups, their responses to the nine questions would be different, since they will have different 
resources available (e.g., financial or technical capabilities). However, executives can use the nine questions and their response options to guide the systematic selection of a suitable differentiation strategy for their company when entering the sharing economy. Besides functional values, a close physical interaction among the actors in the sharing economy allows for the creation of experiential and social values. However, we have learned that the type of value the platform generates for users is not sufficient to substantiate the decision for a suitable differentiation strategy.

We recommend the three actions described below for successfully implementing the differentiation strategy, regardless of whether the technology, partnership, or user-experience strategy has been selected.

\section{Leverage Users for Your Selected Strategy}

Users are part of value creation in the sharing economy. Thus, they should also be involved in implementing a firm's selected differentiation strategy. When following a technology differentiation strategy, users could be used to increase operational efficiency by delegating tasks that would otherwise be performed by service staff. For example, DriveNow's unique technology allows users to see the fuel level of a vehicle before booking and they are offered 30 free minutes for refueling vehicles with an empty tank. This not only reduces the costs for service staff, but also reduces downtimes for maintenance and refueling.

In another example, the peer-to-peer car sharing service SnappCar has a value-adding partnership with the car rental company Europcar. Both use each other's customer bases for cross-selling 12-month rental offers for Europcar's vehicles, with the caveat that the vehicles have to be shared on SnappCar's platform twice a month. This partnership not only increases the supply on the platform, but also attracts new customers who otherwise wouldn't have used SnappCar. BlaBlaCar even goes one step further and leverages the users as part of the user experience to differentiate its business.

These examples demonstrate the variety of options sharing economy organizations have when leveraging users for differentiating the business. However, effectively leveraging users for the selected differentiation strategy requires a fit with the promised values of the service. No matter how users are leveraged for the differentiation strategy, sharing economy firms must also ensure sufficient incentives for contributions from the user side (e.g., coupons, time, or quality benefits).

\section{Leverage Physical Elements for Your Sharing Offer}

In contrast to pure digital platforms, the sharing economy blurs the boundaries between the physical and virtual worlds by using digital platforms to facilitate the sharing of physical products. The physical element of sharing offerings not only allows for the creation of value that goes beyond functional value (e.g., social or pleasurable), but also enables sharing economy firms to leverage different advantages of physical resources.

As mentioned above, sharing economy organizations can use each other's physical resources to directly enhance their service offering (e.g., access to parking spaces for car sharing services) or to improve the service experience (e.g., access to unique resources such as upmarket apartments). For other sharing transactions, firms should carefully design the physical handover of the shared resource. When leveraging technology, they could increase efficiency by deploying devices such as smart locks (e.g., for granting easy access to apartments) or smart handover boxes (e.g., to circumvent the need for the resource provider and consumer to meet in person). Partnerships with physical businesses with long opening hours, such as restaurants or petrol stations, to store the shared resource could be an alternative means for handing over the physical goods. The physical handover can also be exploited to differentiate through user experience. For instance, meeting new people and having a nice conversation when the owner hands over the shared resource (e.g., a camera or a power drill) to the consumer could be a desirable part of the service experience.

Regardless of the differentiation strategy selected, sharing economy organizations shouldn't underestimate the potential for leveraging the physical element of sharing transactions and use it to their advantage. 


\section{Design the Sharing Platform to Facilitate a Physical Experience that Matches Users' Expectations}

Because sharing offerings encompass digital and physical interactions, the sharing platform alone doesn't shape the overall experience. The main part of the transaction takes place in the physical world and lies outside the influence of the platform.

However, the design of the platform shapes the expected manner of interaction between resource provider and consumer. For instance, Uber's focus on technology and efficiency means that passengers don't have to personally coordinate with drivers when booking a ride, because both the driver and the passenger know the necessary details of the ride (i.e., the destination and estimated price) upfront.

Although coordination via the platform is important, both providers of the resources and resource consumers, and the shared resource itself, are also an important part of the overall experience, especially if a sharing platform aims to create social or experiential value. If, for instance, someone shares a ride booked via BlaBlaCar, the interaction among the driver and other passengers, as well as the condition of the shared car, fundamentally influence the experience of traveling together. Thus, sharing economy firms must design their platforms to mitigate uncertainties relating to the sharing experience and facilitate an efficient selection of a sharing offer that fits users' preferences and expectations. BlaBlaCar's platform, for instance, provides mechanisms that inform users about the expected sharing experience by highlighting drivers' and passengers' personality traits and preferences in user profiles (e.g., preferred level of interaction), as well as pictures and descriptions of the car.

The need to provide an experience that matches users' expectations highlights that sharing platforms must be designed to ensure there is a strategic fit between the selected differentiation strategy and the way transactions are initiated and processed. Platforms must include mechanisms that facilitate a physical experience that matches users' expectations and reduce uncertainties for both the provider and the consumer of a shared resource.

\section{Concluding Comments}

This article provides advice for managers of firms seeking to enter the sharing economy on the challenge of selecting a suitable differentiation strategy. Our research shows that to succeed in the sharing economy firms need to differentiate themselves, and to that end, we have identified three main differentiation strategies. To assist managers in the complex task of selecting an appropriate differentiation strategy, we offer a set of nine questions that they should consider. The answers to these questions will help to identify which differentiation strategy is suitable for an organization's specific circumstances.

Legislators' and regulators' responses to growing environmental concerns (e.g., a ban on driving diesel vehicles) mean that new sharing economy offerings could play an increasingly important role in daily life. To ensure their survival, firms entering the highly competitive sharing economy should leverage technology in an appropriate manner and systematically select a suitable differentiation strategy.

\section{Appendix A: Research Method}

To identify the differentiation strategies and their underlying characteristics, we collected data from sharing economy organizations operating in Germany. Between October 2015 and November 2016, we conducted interviews with two industry experts and 17 senior representatives of nine organizations (see table below). We used a semistructured interview guide that included open questions about the business model, the role of technology, competitive actions, and current and future challenges for the organization. On average, each interview lasted an hour.

\section{Research Interviewees}

A summary of the nine organizations is set out below:

- "RideForHireCo" is an on-demand ridefor-hire service founded in 2009 and operates globally in over 70 countries and approximately 600 cities. It mediates on-demand rides between individuals and offers limousine services via a smartphone app. It doesn't own the vehicles. 


\begin{tabular}{|c|c|c|c|}
\hline & Organization & Function & Date \\
\hline \multirow{2}{*}{1} & RideForHireCo* & General Manager & Dec 2015 \\
\hline & RideForHireCo & Head of Public Affairs & Nov 2015 \\
\hline \multirow{3}{*}{2} & RideSharingCo & General Manager & Nov 2015 \\
\hline & RideSharingCo & Head of Business Development & May 2016 \\
\hline & RideSharingCo & Head of Marketing & Jul 2016 \\
\hline \multirow{2}{*}{3} & CarSharing1Co & Head of Business Development & Sep 2015 \\
\hline & CarSharing1Co & Operational Manager & Sep 2015 \\
\hline \multirow{3}{*}{4} & CarSharing2Co & General Manager & Nov 2015 \\
\hline & CarSharing2Co & Head of Sales & Jun 2016 \\
\hline & CarSharing2Co & Head of Operations & May 2016 \\
\hline 5 & PrivateCarSharingCo & General Manager & Jun 2016 \\
\hline 6 & ScooterSharingCo & General Manager & Nov 2016 \\
\hline 7 & TaxiSharingCo & Business Development Manager & Apr 2016 \\
\hline \multirow{3}{*}{8} & ItemSharingCo & Head of Marketing and Sales & May 2016 \\
\hline & ItemSharingCo & Head of Operations & May 2016 \\
\hline & ItemSharingCo & Head of Technology & May 2016 \\
\hline 9 & ParkingspaceSharingCo & General Manager & Oct 2015 \\
\hline- & Collaborative network & Industry Expert & Apr 2016 \\
\hline- & Collaborative network & Industry Expert & Apr 2016 \\
\hline
\end{tabular}

- "RideSharingCo" is a long-distance ridesharing service founded in 2006 that operates worldwide. It connects drivers with passengers who want to travel together between cities and are willing to share the cost of the ride. The service is available via a smartphone app, webpage, and mobile internet.

- "CarSharing1Co" is a free-floating B2C car sharing service founded in 2011 that operates over 5,000 vehicles (which it owns) in 12 cities and seven countries worldwide. Apps for mobile devices allow users to locate, reserve, open and start vehicles.

- "CarSharing2Co" is a regional B2C car sharing service founded in 2015 that operates in one city in Germany. It offers access via a smartphone app to approximately 70 vehicles (which it owns) distributed across 30 railway stations in the city. Additionally, the company offers access to vehicles of more than
170 partner car sharing organizations operating regionally.

- "PrivateCarSharingCo" is a P2P car sharing service founded in 2010 that operates throughout Germany. It connects private car owners and individuals who have a temporary need for a car. The duration of the rental varies from four hours to several days.

- "ScooterSharingCo" is a B2C scooter sharing service founded in 2014 that operates in two cities in Germany. It owns the scooters and provides access to them via a smartphone app. Similar to "CarSharing1Co," the scooters can be parked anywhere in the two cities.

- "TaxiSharingCo" is a taxi sharing service founded in 2014 that operates in two cities in Germany. Via a smartphone app, it mediates taxi rides between passengers who are prepared to share the cost. All rides are provided by traditional taxi companies. 


\begin{tabular}{|c|c|}
\hline Organization & Main Differentiation Strategy \\
\hline RideForHireCo & Technology \\
\hline RideSharingCo & User experience \\
\hline CarSharing1Co & Technology \\
\hline CarSharing2Co & Partnership \\
\hline PrivateCarSharingCo & User experience \\
\hline ScooterSharingCo & Technology \\
\hline TaxiSharingCo & Partnership \\
\hline ItemSharingCo & User experience \\
\hline ParkingspaceSharingCo & Partnership \\
\hline
\end{tabular}

- "ItemSharingCo" is an item sharing service founded in 2015 that operates in one city in Germany. It connects people who are willing to share items such as photographic, gaming, or outdoor equipment with other individuals. The rental time varies from one day to several days.

- "ParkingspaceSharingCo" is a parking space sharing services founded in 2013 that operates throughout Germany. It mediates parking spaces available from private individuals and commercial organizations (e.g., for trucks) via a smartphone app or desktop PC. The duration for renting the parking spaces varies from one hour up to several months.

To verify the statements made by the interviewees, we used secondary data sources, including websites, press releases, news stories, and other company materials.

Insights gained from the nine sharing economy companies operating in Germany allowed us to identify their value propositions, use of technology, and their differentiation strategies (see table below).

Finally, we selected three cases from the nine organizations to include in this article, as prototypical examples of each of the three differentiation strategies.

\section{About the Authors}

\section{Alexander Frey}

Alexander Frey (frey@is-augsburg.de) is a research fellow in the Chair of Information Systems and Management at the University of
Augsburg. He holds a Ph.D. from the University of Augsburg, Germany, and a Master's degree in information systems from the Technical University of Munich (TUM). His research addresses the sharing economy, in general, and the value creation of sharing economy platforms, in particular.

\section{Manuel Trenz}

Manuel Trenz (manuel.trenz@wiwi.uniaugsburg.de) is an assistant professor at the University of Augsburg, Germany. His research focuses on IT-driven transformation and disruption, as well as on the implications of innovative IT services on user and organizational behavior. His work has appeared in Journal of Management Information Systems, European Journal of Information Systems, Information \& Management, and others.

\section{Daniel Veit}

Daniel Veit (veit@wiwi.uni-augsburg. de) is a professor and chair of information systems and management in the Department of Business Administration of the Faculty of Business and Economics at the University of Augsburg, Germany. He is also a visiting professor in the Department of Digitalization, Copenhagen Business School, Denmark. He holds a Ph.D. in management from Karlsruhe Institute of Technology, Germany. His research interests include sustainability through digital technologies, digital business models, digital entrepreneurship, pricing, value creation, competition, and data privacy. 